\title{
Correction to: Introducing statistical consistency for infinite chance constraints
}

\author{
Imen Zghidi ${ }^{1}$ - Brahim Hnich ${ }^{2,3}$ • Abdelwaheb Rebai ${ }^{1}$
}

Published online: 5 May 2018

(C) Springer International Publishing AG, part of Springer Nature 2018

\section{Correction to: Ann Math Artif Intell https://doi.org/10.1007/s10472-018-9572-3}

The original version of this article unfortunately contained a mistake. The name "Abdelwahad Rebaii" should be corrected to "Abdelwaheb Rebai".

The original article has been corrected.

The online version of the original article can be found at https://doi.org/10.1007/s10472-018-9572-3.

Imen Zghidi

zghidi.imen@gmail.com

Brahim Hnich

hnich.brahim@gmail.com

Abdelwaheb Rebai

Abdelwaheb.Rebai@fsegs.rnu.tn

1 Modils Research Lab, FSEG, University of Sfax, Sfax, Tunisia

2 CES, ENIS, University of Sfax, Sfax, Tunisia

3 Department of CS, Monastir University, Monastir, Tunisia 